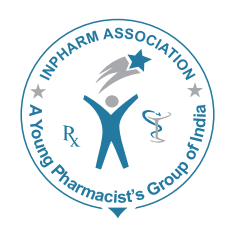

\title{
JVP
}

\section{Pharmacy Education in India: Strategies for a Better Future}

\author{
Jishnu V, Gilhotra RM, Mishra DN \\ Department of Pharmaceutics, School of Pharmacy, Suresh Gyan Vihar University, Jaipur, \\ ${ }^{I}$ Guru Jambheshwar University of Science and Technology, Hisar, India \\ Address for correspondence: Dr. Ritu M Gilhotra; E-mail: ritugilhotra@yahoo.co.in
}

\begin{abstract}
In this world of specialization and globalization the pharmacy education in India is suffering from serious backdrops and flaws. There is an urgent need to initiate an academic exercise aimed at attaining revamping of curriculum, keeping in pace with current and emerging trends in the field of pharmacy. Unfortunately all these years, enough emphasis was not laid on strengthening the components of Community Pharmacy, Hospital and Clinical pharmacy, while designing curriculum at diploma and degree levels of teaching. The curriculum followed by almost all universities in India are no were up to the world standards and students are still getting the 20-30 yrs older compounding practical exposure in labs during the graduation level. The article emphasises the concept of innovation ecosystems and quality management. Application of TQM to the educational system improves the present situation. The counseling system which serves to be the gateway of the students for entry into the profession should be brought under the scanner. Introducing specializations at the graduation level will result in professional expertise and excellence. Education is a customer focused industry and every student should be capable of evaluating themselves for continuously improving their quality and professionalism. Teacher focused mastery learning should give away to student focused smart learning. An educational institution should provide the student with a stress-free atmosphere for learning and developing his intellectual capabilities. Every college should have a counseling centre to address the problems of students in their academic and personal life. An emphasis on the concept of quality teacher is included. Revival of the pharmacy education in India is the need of the hour which in turn will pave the way for the up gradation of the pharmacy profession in the country.
\end{abstract}

Key words: Education, innovation ecosystems, pharmacy, total quality management

\section{INTRODUCTION}

Innovation has become the watchword in every aspect of life all over the world. The ability of a nation to use and create

\begin{tabular}{|l|l|}
\hline \multicolumn{2}{|c|}{ Access this article online } \\
\hline Quick Response Code: & \\
\hline & Website: \\
\hline & www.jyoungpharm.in \\
& DOI: \\
\hline
\end{tabular}

knowledge capital determines its capacity to empower and enable its citizens by increasing human capabilities. In the next few decades, India will have the largest set of young people in the world. The beginning of pharmaceutical education in India was initiated at the Banaras Hindu University was back in 1932 by Professor M.L. Schroff. From there it was a long journey of almost 80 years for this profession in this country and the question is where we stand in the international scene. Following a knowledge-oriented paradigm of development would enable India to leverage this demographic advantage. In the words of our Prime Minister, "The time has come to create a second wave of institution building and of excellence 
in the field of education, research and capability building so that we are better prepared for the $21^{\text {st }}$ century. With this broad task in mind, the National Knowledge Commission (NKC) was constituted on $13^{\text {th }}$ June 2005 with a time-frame of three years, from $2^{\text {nd }}$ October 2005 to $2^{\text {nd }}$ October 2008. In order to achieve this task we need to strengthen the base of our educational system so that the height of the pyramid of excellence could be enhanced. ${ }^{[1]}$ In this world of specialization and globalization the pharmacy education is suffering from serious backdrops and flaws. The potentials for growth of pharmacy profession is enormous, if we are prepared to upgrade our standards to international and global expectations. ${ }^{[2]}$ The curriculum followed by almost all universities in India are no were up to the world standards. ${ }^{[3]} \mathrm{In}$ the past one decade the technical education in India has spread its roots at an astonishing rate particularly the pharmaceutical field. South India nourished the mushrooming of pharmacy colleges during the initial part of the decade which seems to have paved the way for the alarmingly low number of choosers for this profession in the last phase of the decade. There is an overall decrease in admissions to professional courses particularly in undergraduate course (B. Pharm) in pharmacy during the last three academic years. It is a serious concern that $40 \%$ of the seats are lying vacant both in under graduate and postgraduate courses across the country. The placement in the sector has also gone done. ${ }^{[1]}$ The Education Regulation of PCI which governs diploma education in India has not undergone any updation since 20 years. ${ }^{[4]}$ The students are still getting the 20-30 yrs older compounding practical exposure in labs during the graduation level. The current frame work of pharmacy education in India produces outdated and unskilled professionals. The products of this form of education lack the much needed professionalism and rational thinking. 4 yrs of education in graduation level does not even make them fit for dispensing drugs confidently in a drug store. This is one of the main reasons behind pharmacy being an under developed profession in India. The situation is pathetic and through this article we are proposing some novel ways to improve this situation. We also suggest the application of TQM and innovation ecosystems in pharmacy education. We urge all the pharmacists to be a part and parcel of this rejuvenation process. The mushrooming growth of pharmacy colleges in India has contributed to the deterioration of in the standards of pharmacy education in India. ${ }^{[5]}$ It has become obligatory that the pharmacy colleges have to improve their status to sustain their existence.

\section{Flaws in the present system}

- Entry of unqualified and non-meritorious students into the course.

- Non focused and unspecialized way of learning.
- Out dated curriculum and educational regulations. ${ }^{[3]}$

- Lack of industrial and clinical exposure. ${ }^{[5,6]}$

- Unskilled ways of practical and lab training in the institutes.

- Research output from Indian educational labs rarely lead to commercialization and revenue generation.

- Given the market needs for trained man power, teaching takes total priority over research in our universities.

- Institutional base of research in India is extremely narrow serious research is limited to a few 'elite' institutes.

\section{How to improve the situation?}

Every college should provide the students an atmosphere to nourish his internal skills and qualities. A system should be devised so that each and every student gets an opportunity to freely think and develop his skills to the maximum. Professionalism can be cultivated only through rational ways of thinking and performing. Students should come out with their ideas and suggestions in any aspect of education and especially be focused on innovative research. Most of our students are lacking an initial pull, which should be given by the teachers or the college. Students should also be trained to improve their presentation skills and their personality.

Coming to the educational aspect, much emphasis should be given to industrial and practical exposure. Clinical and practical training should be given more importance and made a part of the curriculum. ${ }^{[7}$ Research oriented way of learning is more effective rather than mugging up a lot of theory. ${ }^{\left[{ }^{[8]}\right.}$ The knowledge of a pharmacy student should be current and always the updation of his knowledge is necessary. He should be aware of what are the latest changes going in the field of pharmacy. A student should learn to evaluate himself and try to continuously improve his knowledge levels. Here comes the importance of commitment and awareness which are the strong elements of TQM. Each and every person being a part of an institution should be aware of the task assigned to him and be committed to do the work in a perfect manner. Here we are discussing mostly about the changes that should be introduced at the educational aspect.

\section{INSIGHT INTO CONCEPT OF INNOVATION ECO SYSTEM}

The concept of the innovation system stresses that the flow of technology and information among people, enterprises and institutions is key to an innovative process. It involves the interaction between the elements, who indeed should turn an idea into a process, product or service resulting in national economic growth. According to Chris Freeman 
the first person to use the expression 'National System of Innovation' was Bengt-Ake Lundvall. ${ }^{[9]}$ Innovation ecosystems refer to the inter-organizational, political, economic, environmental and technological systems through which a milieu conducive to business growth is catalyzed, sustained and supported. Innovation ecosystem is an integrated approach for development. ${ }^{[1]}$ Innovation is something that generates value. Innovators must be challenged to produce solutions that society needs. A basic representation of how an innovative ecosystem functions is conveyed through the Figure 1. Innovative solutions or research with consequences and potentials must be nurtured and rapidly applied. Inventions will become innovations when they produce results which are beneficial to human race. Innovation culture and entrepreneurship are the two key elements for building a successful ecosystem. A dynamic innovation ecosystem is characterized by a continual realignment of synergistic relationships of people, knowledge and resources that promote harmonious growth of the system in agile responsiveness to changing internal and external forces. The Indian universities and institutions should change their mind set to promote innovation culture by creating an environment and encouraging young minds with ideas and thinking out of box approaches. ${ }^{[1]}$

Creating economic value from scientific research needs an Innovation Ecosystem having three nodes: ${ }^{[10]}$

- Node 1: Inspire/Invest - an entity (company) with a vision and mandate to inspire and invest in individuals and institutions.

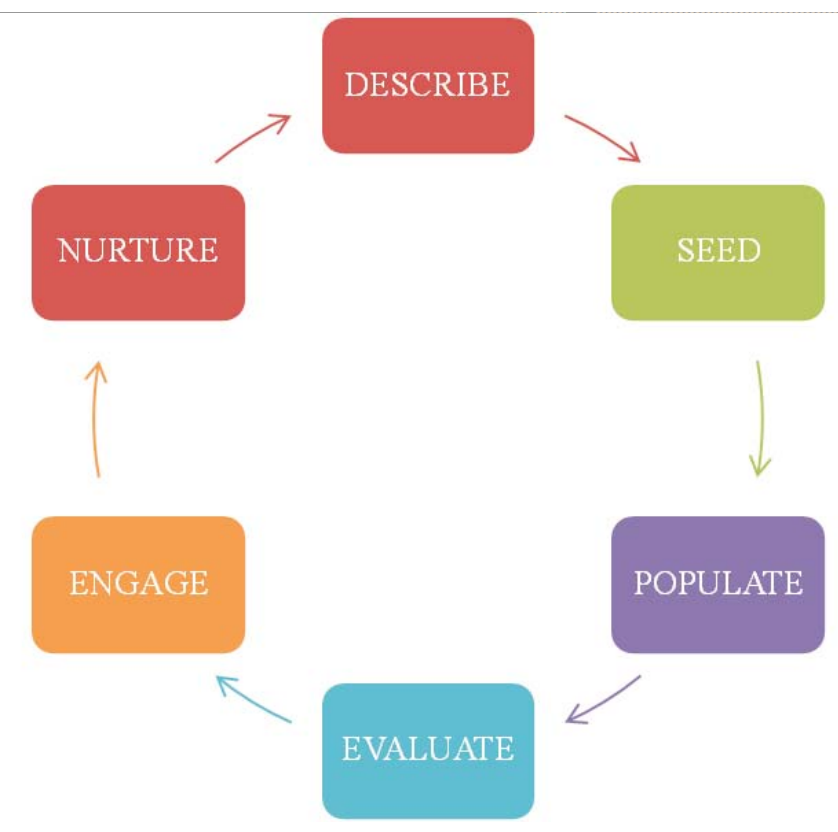

Figure 1: Representation of an innovation ecosystem cycle
- Node 2: Invent/Innovate - an entity (institute) to carry out quality scientific and technological research.

- Node 3: Incubate/Market - an entity (company) to convert research output to products and services of economic and social value.

The economic gains are fed back into the ecosystem to make it stable, sustainable and growing.

The role of universities in creating regional innovation ecosystems:

1. Focus on grand challenges.

2. The strong role of universities is crucial: Based on Knowledge Triangle, i.e. Synergy between research, education and innovation.

3. Modernize the Triple Helix cooperation: University Industry - Cities.

4. Living labs and user-driven innovations: Focus on people and process development.

\section{INTERNATIONAL PLAYERS AND THEIR STRATEGIES}

During the present work we have been researching on the strategies adopted by the international players working with the aim of education and research reformation. We came across some elite organizations with this novel mission of assessing the educational systems and policies to keep up to the current standards. We believe the strategies adopted by them, when applied to the Indian scenario can create the needed phase shift.

The International Association for the Evaluation of Educational Achievement (IEA) is an independent, international cooperative of national research institutions and governmental research agencies. ${ }^{[1]}$

Through its comparative research and assessment projects, IEA aims to:

- Provide international benchmarks that may assist policy-makers in identifying the comparative strength and weaknesses of their educational systems

- Provide high-quality data that will increase policymakers' understanding of key school- and non-schoolbased factors that influence teaching and learning

- Provide high-quality data which will serve as a resource for identifying areas of concern and action, and for preparing and evaluating educational reforms

- Develop and improve educational systems' capacity to engage in national strategies for educational monitoring and improvement

- Contribute to development of the world-wide community of researchers in educational evaluation 
The Programme for International Student Assessment (PISA) is an internationally standardized assessment that was jointly developed by participating economies and administered to 15 -year-olds in schools. It is coordinated by the Organization for Economic Co-operation and Development (OECD), with a view to improving educational policies and outcomes. The National Assessment of Educational Progress (NAEP) is a periodic assessment of student progress conducted in the United States by the National Center for Education Statistics, a division of the U.S. Department of Education. Main NAEP reports statistical information about student performance and factors related to educational performance for the nation and for specific student groups in the population. All these organizations mentioned are assessing the student population at school level. We would like to bring to the notice of national policy makers in the pharmaceutical sector, that it is high time we should clearly do some renovation work following the pattern of the above discussed players. We strongly recommend the adoption of policies and strategies followed these associations and setting up of national level organizations assessing the pharmaceutical education progress and assessing the pharmacy students of the country and saving this profession from a great fall.

\section{COUNSELING SYSTEM TO BE BROUGHT UNDER THE SCANNER}

The present counseling system proves to be the first and foremost reason for the degradation of the profession in the country. The system creates a situation in which anyone who has money can get a seat in B. Pharm without the basic qualifications. The system has to be scrutinized and some regulations have to be made which assures that the meritorious students are entering into the profession. A centralized allotment procedure (CAP) is to be introduced to regulate the entry of students into the pharmacy stream, which is purely based on the merit all throughout the country.

\section{SPECIALIZATION: AGENDA FOR A BETTER FUTURE}

We are proposing the idea of introducing specializations at graduation level in pharmacy. Like the other technology courses like B.E/B. Tech, we should also have a provision for specialization from graduation level in all the conventional branches of pharmacy. It is time to think of for a person holding a B. Pharm [pharmaceutics] or B. Pharm [pharmacology] degree.
What does it provide?

- Professional excellence and expertise.

- It upgrades the status of the profession in the country.

- Opportunity for students to choose their subject of interest.

- Rational and logical way of career development.

- Focused and job oriented approach towards education.

\section{How to implement this?}

Proposal for a new curriculum is not at all an easy task. Introducing specializations doesn't mean devoiding the student from pursuing the basic knowledge a pharmacist should have. The first 2 yrs of graduation should focus on providing all the basic education needed for a pharmacist as per the norms of educational regulations of Pharmacy council of India. The final 2 yrs should be based on the subject of specialization and its practical applicability. Every 5 yrs updation of the curriculum should be made a rule in the country. There should also be some provisions for choosing the subject of interest after the $1^{\text {st }} 2$ yrs at graduation level.

This also makes the education at post-graduation level more research oriented and gives the student chances to think for super specializations simultaneously. In this way education our students will have deeper knowledge in the concerned subject and it nourishes the professionalism within them.

\section{QUALITY ASSURANCE IN PHARMACY EDUCATION}

Quality is the key word for success of an institution. It is the essence for survival of a professional institution like pharmacy. ${ }^{[12]}$ The vision and mission of the institution speak of quality as an ultimate goal. Recognizing the need to support and strengthen pharmacy education worldwide, in November 2007, International Pharmaceutical Federation (FIP), in collaboration with the World Health Organization (WHO) and United Nations Educational, Scientific and Cultural Organization (UNESCO), formed the Pharmacy Education Taskforce. ${ }^{[13]}$ The Taskforce is a coordinating body of organizations, agencies, institutions, and individuals with the shared goal of catalyzing actions to develop pharmacy education. The purpose of the Taskforce is to oversee the implementation of the Pharmacy Education Taskforce Action Plan 2008-2010. The Action Plan aims to enable the sustainability of a pharmacy workforce that is relevant to local needs. The Action Plan is dedicated to three domains of action: quality assurance, academic and institutional capacity, and competency and vision for pharmacy education. 
Founded in 1912, the International Pharmaceutical Federation (FIP) is the global federation of national associations of pharmacists and pharmaceutical scientists and is in official relations with the World Health Organization (WHO). ${ }^{[14]}$ Through its 124 Member Organizations FIP represents and serves more than two million practitioners and scientists around the world. Throughout its almost 100 year history, FIP's priorities have expanded both literally and figuratively to meet the needs and expectations of the profession in expanding healthcare services and integrating emerging scientific developments. Changes in pharmacy and the emergence of Pharmacy Practice as a cornerstone of the profession have lead FIP to become globally visible for its advocacy on behalf of the role of the pharmacist in the provision of healthcare, while still maintaining its grounding in the pharmaceutical sciences.

It is the belief of FIP that in order to support the development of an adequate and appropriate pharmacy workforce and the academic and institutional infrastructure to deliver the required competency based education and training, each country should have its own standards based system for the quality assurance of pharmacy education. The QA system should:

- Reflect the vision for pharmacy practice and education that has been developed through profession wide consensus.

- Allow appropriate input from all stakeholders, including students and the public.

- Ensure that educational programs are evidence and competency-based, of high quality and meet the needs of the people, the pharmacists and their country.

- Evaluate programmatic outcomes as well as institutional structures and processes.

- Be transparent and be free of inappropriate influences and appearances of conflicts of interest in its development and implementation.

- Promote and foster self-assessment and continuous quality improvement of educational institutions.

- Be accountable to the appropriate governmental authorities.

\section{AN EMPHASIS ON APPLICATION OF TQM IN PHARMACY}

TQM in education surfaced in 1988 at Mt. Edgecombe High school in Sitka, Alaska, when David Langford, the school's technology teacher/coordinator, applied Total Quality concepts in his classes. ${ }^{[15]}$ Since then TQM has become increasingly popular in education, as evidenced by the plethora of books and journal articles published in the topic after 1990. TQM has also spread into mainstream of educational organizations. The Association for Supervision and Curriculum Development, for example, devoted its entire November, 1992 issue of its journal, Educational Leadership, to the quality movement in education. In support of the TQM initiatives in education, Crawford and Shutler applied Crosby (1984) model to suggest a practical strategy for using TQM principles in education. ${ }^{[15]}$ Their strategy focused on the quality of the teaching system used rather than on students' examination results. They argue that examinations are a diagnostic tool for assuring the quality of the teaching system. To satisfy the educational needs of students, continuous improvement efforts need to be directed to curriculum and delivery services. From such a perspective, various root causes of quality system failure in education have been identified. ${ }^{[15]}$

Total quality management is becoming the universal mantra/universal medicine in any and every aspect of life. TQM has the solution for all the problems were are facing in day to day life. It is being said as the most powerful managerial tool which has the universal applicability and versatility. ${ }^{[16]}$ The correct way of using this tool is not an easy task and its success totally depends on the way it is being used. TQM is a philosophy for perfection and continuous improvement in services offered to someone or one's own performance. ${ }^{[17]}$ Applying TQM in pharmacy is the need of the time. Here we are suggesting some changes which can improve the current situation by emphasizing on the tool TQM. Education is a fast moving commodity in the market and is mainly business oriented which means it should give some profit to the undertaker. ${ }^{[18]}$ Education also upholds some ethics so that the customer or the students gets the value for the money which they spend. Total quality management (TQM) is a method of improving the effectiveness of an organization by involving every individual at every level within the organization so that they work together. The principles enunciated in TQM are universal and they can be utilized for improving the quality of any product.

\section{Principle of harmonization}

In any organization we can see different levels of hierarchy and compartmentalism. The levels of hierarchy in a pharmacy institution are depicted in Figure 2. TQM should be applied at each and every levels of hierarchy. The different hierarchy levels should work in a harmonized manner towards the same goal improving the quality of service provided to the students (customers) and thereby improving the quality of the institution. The higher levels of hierarchy have the herculean task of designing a flawless TQM system. Coordination between the different levels makes a system more powerful and successful. As we have already said TQM is a continuous process of improvement. ${ }^{[16]}$ Sticking 


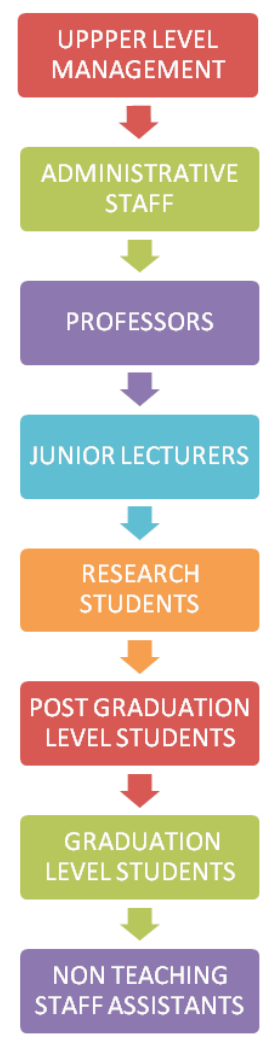

Figure 2: The levels of hierarchy in a pharmacy institution

on to some particular standards or regulations is not at all sufficient and continuous improvement is necessary. Continuous monitoring of the functions of the lover levels should be done by the upper level directly or by setting up some monitoring committees. The monitoring committees should evaluate the functioning of each hierarchy level and prepare a report which should be discussed in the group.

\section{Importance of monitoring committee reports}

- Indicates the functioning of each and every levels of hierarchy.

- Discussion on the report identifies the flaws in the system.

- It helps in continuous evaluation and continuous improvement of the system.

- It records the progress of the levels in their concerned work aspects.

\section{RELATION BETWEEN THE DIFFERENT LEVELS}

The functions of each and every level are interrelated and inter dependent. The upper level proposes the basic way of functioning of the system and the lower levels follow it. The levels which are directly linked with the students (customers) are the lecturers who perform the most important functions of the whole system. The quality of education provided to the students dependant mostly on the availability of qualified and experienced staff in an institution. Providing the qualified staff to the students is the job of upper level management. The presence of more experienced staff in the college gives the students an excellent atmosphere for learning in a more focused and interesting way. It is the sole duty of the senior staff to coordinate all the activities related with improving the quality of education in an institution. Working as a team makes the process more easy and effective rather than a compartmentalized effort. The senior staff should guide the junior staff in their activities and help them to improve their ways to teaching and guidance. The senior students of the college should lend a helping hand to their junior students in improving their quality. Team work is essential in every aspect of educational life in a college. The assistant staff in the college has also an important role to play. They are directly linked to the students by helping them in doing their practical and research works in laboratories. They have the important work of handling the drug store and maintaining the equipments in the labs.

\section{Self-evaluation charts}

Self-evaluation is an important part of TQM. Education is a customer focused industry. Every student should be capable of evaluating themselves for continuously improving their quality. They must have a thorough understanding of their strength and weakness. Self-evaluation charts (SEC) is a statistical data which is to be prepared by every student in the form of a graph or flow chart which is an indication of his progress in education related aspects. It seems to be a simple concept but it is a powerful tool. Preparation of SEC'S should be made compulsory from graduation level itself in all colleges. Periodic analysis of the chart should be done by the teacher in the presence of the student and discussions should be conducted and suggestions to improve should be put forward.

\section{Applications of SEC's}

- A student gets the opportunity to evaluate himself.

- It is an indication of a student's progress in academics or related activities.

- It is also helpful to faculty members to analyze the progress of a student in academics.

E.g.: Recording of marks for a student in a particular session in seminars, assignments etc. represented in Figure 3.

Seminars and presentations as powerful tools in quality education

Seminars and presentations turns about to be the most 


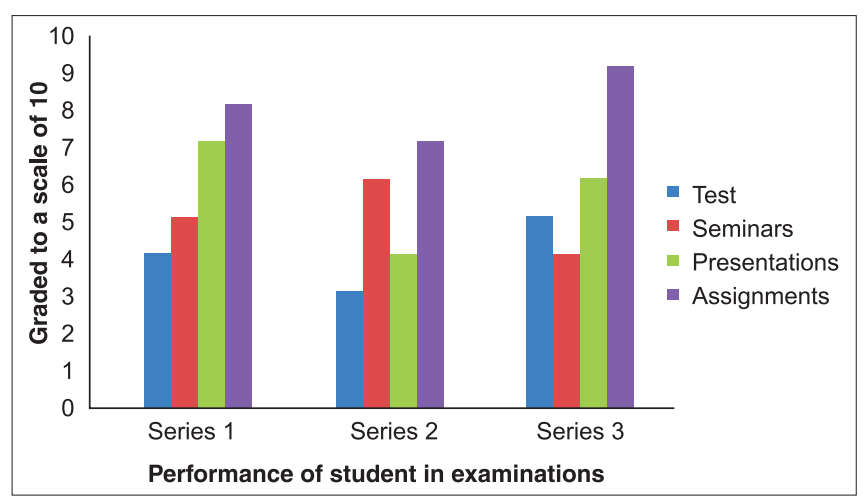

Figure 3: Model for a self-evaluation chart

important tools in improving the quality of education in an institution. It is very important for a student to be skilled in making presentations and giving a seminar on a topic. Seminars should be given especially on the topics which are of current importance and recently under research. Seminars should be made compulsory from graduation level and should be a criterion for evaluation of the students.

\section{Benefits}

- It improves the understanding of the subject.

- Researching attitudes of the students are developed.

- Improves presentation, listening and reading skills of the students.

- Inculcates professionalism.

- Overview of subjects in an easy and comfortable way.

- Interesting way of learning.

- Information sharing becomes easier and the subject becomes more digestable to the students.

\section{Suggestions}

For graduation level: Minimum 5 seminars in an academic year. For post-graduation level: Minimum 30 seminars in an academic year.

A transformation from mastery learning to smart learning

In traditional classrooms, teachers follow this sequence:

$$
\text { PLAN } \Rightarrow \text { TEACH } \Rightarrow \text { TEST }
$$

The TQM alternative is:

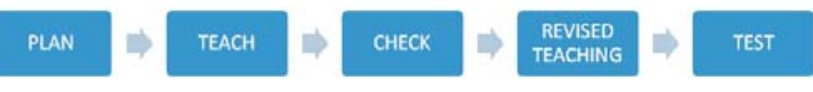

The TQM alternative also suffers from drawbacks. The proposed alternative is a teacher centered and there is no role for the student in the whole process. The step check is confusing too as it don't provide the way to check the students. We are proposing a newer student centered mastery plan based on TQM.

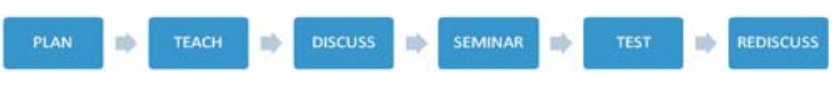

Through discussions the student can get a clear idea of the concept and is a way to put forward his doubts. The student plays the central role in the proposed alternative and gets the opportunity to device his own way of learning. During the discussions, the students who have mastered the material can help the students who have achieved mastery. Smart learning proves to be a more useful alternative

\section{PROFESSIONAL DISCRIMINATION DUE TO LACK OF CLINICAL EXPOSURE}

All over the world the profession of pharmacy has matured into a clinical profession. It has transformed itself from a product oriented to patient oriented profession. The World Health Organization (WHO) in its initiative in 1997-98 prepared a global health policy frame work so that all health professionals are appropriately and adequately prepared to face the health problems of $21^{\text {st }}$ century ${ }^{[1]}$ Clinical pharmacy is one of the most important branches in pharmacy. The present curriculum includes all the theoretical aspects of the particular subject but unfortunately the practical exposure is an absolute zero. This is the most important reasons for the professional degradation and discrimination of pharmacists in the country. We should include case studies in the graduation level in the subject of clinical pharmacy which can enrich our practical exposure in the medical field and also help us to be recognized as a profession of prime importance in the health care system in India. ${ }^{[1]]}$ Working with some case studies in the hospitals gives the students a clear idea of what happens in a health care system, how the theoretical part differs from the practical work outs. The actual treatment procedures in the clinical set up is far different from what we study in theory and is necessary that a clinical pharmacist should be in touch with all this procedures. The curriculum should be revised so that the student gets the opportunity to be accustomed with the actual situation in a clinic rather than mugging up chunks of theory.

\section{COUNSELING AND COMMUNITY SERVICE CENTERS}

An educational institution should provide the student with a stress free atmosphere for learning and developing his intellectual capabilities. But the situation is just the other way round in many institutions. The students are under 
stress due to the work over loads and inefficient time management, totally the academic life becomes horrible for them. Here comes the importance of counseling and its benefits to the students. Every college should have a counseling centre to address the problems of students in their academic and personal life. The centre should hire the services of some persons eminent in this field and also the lectures and senior students of the college should be involved in the functioning of the counseling centre.

\section{Benefits of counseling centre}

- Gives the students an opportunity to share their problems.

- They can get solutions for their queries in academics and their personal life.

- It can improve the confidence of the students.

- Mental strengthening provides the stress free atmosphere for the student.

- An overall improvement in the student intellects especially in academics.

- Creating some smart professionals in the institution.

What is community service learning?

Community Service-Learning (CSL) ${ }^{[20]}$ is an educational approach that integrates service in the community with intentional learning activities. Within effective CSL efforts, members of both educational institutions and community organizations work together toward outcomes that are mutually beneficial.

Known by a variety of terms (e.g., service-learning, community-based learning), CSL programs are most effective when they include key elements drawn from experiential education theory, especially developing critical thinking and intentionally facilitating reflection. Carefully designed and implemented CSL programs and courses assist students to make meaning from their community experiences, to connect experience outside of the classroom to more theoretical study, and to develop as individuals in relation to their values, their sense of social responsibility, and their leadership skills.

Community service-learning is new to Indian universities and colleges but has been active in the United States over the past two decades, where it is most commonly referred to as service-learning.

The American Association of Colleges of Pharmacy (AACP), Center for advancement for pharmacy education recommends that in addition to the professional competencies, pharmacy schools should integrate general abilities such as social and contextual awareness, social responsibility, ethical decision making and social interaction into pharmacy curriculum programs. ${ }^{[21]}$ This experience in turn helps to promote a sense of caring for others. To achieve the goal of pharmaceutical care later on in professional life, developing this sense of caring and responsibility is highly essential. ${ }^{[21]}$ What are we waiting for, were is our national pride, policy makers; please keep your eyes and ears wide open to see the world changing before you for some good reasons.

\section{QUALITY TEACHER}

The part played by teachers in the academic life of students is very important. They have the responsibility of guiding the students to improve their intellectual and learning skills. The book The Quality School Teacher by William Glasser centers mainly on this concept of a quality teacher based on TQM principles. The concept provides the use of more brain compatible techniques in teaching. The teacher should be able to provide what the student needs and should be able to bring the student to his maximum caliber. A good academician should always update his knowledge and should be aware of all the novel innovations in the field of pharmacy. For this we suggest that all the lecturers should attend industrial and clinical workshops on a regular and compulsory basis. It would give them the exposure to the latest innovations in the field of pharmacy and that information can be passed on to their students which makes their effort productive. They should also strive to improve their ways of teaching and guiding the students to create a warm and very productive learning environment in the institution concerned.

\section{THE ULTIMATUM}

The article was written with aim of addressing the major issues related with pharmacy education system in India and suggesting some basic level "strategy shift" for improving the situation. We were trying to put forward some simple plans based on quality management. Proposal for a transformation plan have be to devised first and apply the principles of TQM in the transformation plan. The top level bureaucrats and policy makers of India still did not manage to get a bus to the $21^{\text {st }}$ century. Revival of the pharmacy education in India is the need of the hour and a master plan with an international perspective and its immediate implementation is the only solution.

\section{REFERENCES}

1. Kulkarni SK. Creating an innovation ecosystem in pharmaceutical sciences: Adopting today education for tomorrow. Pharma Times 2011;43:14-5.

2. Dave JB. Does bright future await pharmacy students? Pharma Times 2011;43:13. 
3. Lalla JK. Pharmacy education- Challenges ahead: My perception. Indian J Pharm Educ 1999;33:24.

4. Dandiya PC. Pharmaceutical education in India: An introspection for better future. Pharma Times 2011;43:19.

5. Seth PD. Pharma Education in the new millennium. Indian J Pharm Educ 1999;33:93.

6. Shaji J, Chadawar V. Pharmacy education: It's challenges. Pharminfo.net. [2007 Oct 10] [cited 2010 Dec 19]; 5(5): [about 10 screens]. Available from: http://www.pharmainfo.net.

7. Kokate CK. Pharmaceutical Education in India Vision 2010. Indian J Pharm Edu 1999;77:33.

8. Shantanu K. Pharmacy Education: Current problems and suggested solutions. Indian J Pharm Educ 2004;38:154.

9. Freeman C. The 'National System of Innovation' in historical perspective. Cambridge J Econ 1995;19:5-24.

10. kbcrf.co.in [homepage on the Internet]. Chennai. India: KBC research foundation limited; c2009 [cited 2011 April 9]. Available from: http:/ /www. kbcrf.co.in.

11. International Association for the Evaluation of Educational Achievement [homepage on the Internet]. Amsterdam. The Netherlands; IEA Inc. c2007 [cited 2011 April 20]. Available from: http://www.iea.nl.

12. Kokate C. Paradigm Shift in Indian pharmacy education for quality enhancement and sustainable development. Pharma Times 2011;43:17-9.

13. International Pharmaceutical Federation (FIP). Hague. The Netherlands. FIP; [cited 2011 Feb]. Available from: http://www.fip.org.
14. International Pharmaceutical Federation. FIP statement of policy Quality assurance of pharmacy education. Proceedings of FIP Council: 2009.Sep 8; Istanbul. Hague. The Netherlands. FIP; [cited $2011 \mathrm{Feb}$ ]. Available from: http://www.fip.org.

15. Hadi Mohammad Pour, K. Yeshodhara. Total quality management (TQM) in education perception of secondary school teachers [Internet]. [cited 2011 february]: [about 10 screens]. Available from: http://www.ejournal.aiaer.net.

16. Total Quality Management. Chapter 5. [cited 2010 Dec 21]; 138-67. Available from: http://www.wiley.com/college/sc/reid/chap5.pdf.

17. Gilhotra N. TQM and six sigma in health care industry. Pharmabuzz 2009;4:16-20.

18. Rao PG. Radical restructuring of pharmacy education. Indian J Pharm Educ 1995;29:11.

19. Mithal BM. Status of pharmaceutical education in India: Retrospect and prospect. Indian J Pharm Educ 1995;19:22.

20. Canadian Alliance for Community Service-Learning. Ottawa. Canada. CACSL. c2004. [cited 2011 April 20]. Available from: http://www. communityservicelearning.ca.

21. Gharat MS, Achhra CV. Community services: Much needed component in the pharmacy curriculum. Pharma Times 2011;43:16.

How to cite this article: Jishnu V, Gilhotra RM, Mishra DN. Pharmacy education in India: Strategies for a better future. J Young Pharmacists 2011;3:334-42

Source of Support: Nil, Conflict of Interest: None declared. 